\title{
Study of Advances in Management of 68 Cases of Ectopic Gestation
}

\author{
Jalpa U Shah ${ }^{1}$, Dr Sushma R Shah ${ }^{2}$, Dr Megha S Patel ${ }^{3}$, Dr Shashwat Jani ${ }^{4}$, Shachi Joshi ${ }^{5}$
}

\begin{abstract}
Introduction: In recent years due to various reasons and better diagnostic facilities, increased incidence is noted in ectopic gestation. Main objective behind this study is to know the incidence of ectopic pregnancy in various age groups,to study it predisposing factors, its clinical presentation and to study the changing trends of modern obstetric management from radical surgeries to medical and laparoscopic management. Methods: A study of 68 cases of tubal ectopic pregnancy was carried out from August 2013 to July 2014 at a tertiary health care center. Patients managed with following modalities were selected for study. (1) Medical management(MXT) (2) Laparoscopic management :salpingostomy,salpingectomy (3)Laparotomy management: salpingostomy, segmental resection, fimbrial expression, salpingectomy. Results: Lower abdominal pain was most common presenting symptom of ectopic pregnancy in $88 \%$ cases. The classical triad of symptoms( amenorrhea, abdominal pain and vaginal bleeding) was present in only $42 \%$ cases. PID contributed 4\% cases and previous abortion contributed 7\% cases indicating these two as the common risk factors. Ampulla was the commonest site of pregnancy, in $63 \%$ cases. Salpingostomy was performed in this site. $10 \%$ cases were treated medically(methotrexate). These were the cases having unruptured ectopic pregnancy and ectopic mass $<4 \mathrm{~cm}$. laparoscopy was done in $10 \%$ cases and oopn laparotomy in $82 \%$ cases. Conclusions: ectopic pregnancy is a treatable problem. Ultrasonography plays a central role in the diggnosis ad management. Mode of therapy is determined by a combination of clinical symptoms, USG findings and serum BHCG values. Surgical management is still the cornerstone of management of ectopic pregnancy. But new scope of medical and laparoscopic management is also there.
\end{abstract}

Keywords: Advances Management Ectopic Pregnancy Medical Laparoscopic Laparotomy

\section{Ectopic Pregnancy}

When fertilized ovum gets implanted at site other than the normal position of uterine cavity it is known as Ectopic Gestation. It is a leading cause of maternal mortality and morbidity in first trimester and also cause reduced child bearing potential.

Increased INCIDENCE of Ectopic Gestation is due to dramatic rise in $\operatorname{PID}(7-10$ fold) -increased awareness and use of intrauterine devices - ART(Artificial Reproductive Therapy)

Objectives of the study are -study the incidence in various age groups -to study its predisposing factors -to study the different modes of clinical presentation -to study changing trends of modern management from radical surgical method to medical management and laparoscopic surgeries.

Course of Ectopic Pregnancy: Spontaneous resolution -tubal abortion -pelvic hematocoele -hematosalpinx - tubal rupture - rupture followed by secondary abdominal pregnancy.

Diagnostic Modalities for Ectopic Pregnancy

1) Serial B-HCG titre $-66 \%$ rise in $\mathrm{B}-\mathrm{HCG}$ titre is seen at 2 days in normal intrauterine pregnancy(IUP). discriminating zone is $1500 \mathrm{IU} / \mathrm{ml}$ of $\mathrm{B}-\mathrm{HCG}$. At this level IUP must be located. -there is a decrease of $21 \%$ $35 \%$ of B-HCG levels if spontaneous abortion occurs. Slower decease or slow increase suggests Ectopic Gestation -in 17\% patients with ectopic pregnancy BHCG doubling time is normal.

2) Progesterone level -poor diagnostic value $->25 \mathrm{ng} / \mathrm{ml}$ suggests normal IUP. - $<5 \mathrm{ng} / \mathrm{ml}$ suggests abortion. ectopic pregnancy $5-25 \mathrm{ngml}$-limitations include patients undergoing infertility treatment via IVF.

3) Features seen on TVS(Transvaginal ultrasound) Ectopic cardiac activity-> diagnosis is $100 \%$-ectopic gestational sac - strong evidence -ectopic mass \& fluid in POD -> moderately strong evidence

4) Colour Doppler - Ring of Fire Sign seen around a cold uterus is diagnostic of ectopic gestation on colour Doppler ultrasound.

5) Laparoscopy is rarely used for diagnosis. Diagnostic scopy can be converted to therapeutic scopy and treatment can be achieved simultaneously.

\section{Management}

Medical management Selection criteria-mass $<3.5 \mathrm{~cm}-\mathrm{B}-$ $\mathrm{HCG}<4000 \mathrm{mIU} / \mathrm{ml}-<6$ weeks gestational age - absent cardiac activity -no hemoperitoneum -hemodynamically stable patient -well compliant and well counselled patient. Methotrexate regimen-single dose $-50 \mathrm{mg} / \mathrm{m} 2 \mathrm{IM}-\beta \mathrm{HCG}$ on day 4 and 7 should decrease by $15 \%$ of the initial level -if it persists on day 7 , repeat the dose (max 4 doses) -if it decreases do weekly $\beta \mathrm{HCG}$ till Ectopic Pregnancy resolves $(<10 \mathrm{mIU})$.

\section{Materials and Methods}

The study includes a study of $\mathbf{6 8}$ cases of Ectopic Pregnancy in General Hospital over a period of Two Years from August 2013 to July 2015 in Department of Obstetrics and Gynecology.

Main $\boldsymbol{A I M}$ is to study Management of Ectopic Gestation by different modalities including Medical management and Surgical management by Laparoscopy and Laparotomy.

\section{Observation and Discussion}

\section{INCIDENCE: ATVSGH}

Total number of pregnancy 22084

Total number of ectopic 68 


\section{International Journal of Science and Research (IJSR) \\ ISSN (Online): 2319-7064 \\ Index Copernicus Value (2013): 6.14 | Impact Factor (2014): 5.611}

Incidence of ectopic preg. (In pregnancy) $1: 320$

Total no. of delivery 17340

Total no. of delivery (emergency) 5598

Total no. of delivery (register) 11642

Total no. of V. mole 29

Total no. of abortion 1593

Total no. of bleed PV 1045 (44.6\%)

\section{Incidence of ectopic pregnancy in bleeding PV patient} $21.60 \%$

Incidence of ectopic pregnancy is increasing due to increase incidence of pelvic. Inflammatory disease, tubal surgery, popularity of contraceptives, ART etc.

In my study majority of females prefer Oral Contraceptive pills over IUCDs. This may be reason for low incidence of ectopic pregnancies in our population.

\begin{tabular}{|l|l|}
\hline \multicolumn{1}{|c|}{ Clinical profile } & No, of cases(\%) \\
\hline Age in years & \\
20 or less & 12 \\
$21-30$ & 15 \\
$>30$ & 71 \\
\hline Parity & \\
Primipara & 30 \\
Secondpara & 24 \\
Third para & 7 \\
>third para & 7 \\
\hline Symptoms & \\
Lower abdominal pain & 88 \\
Amenorrhoea & 69 \\
Bleeding per vaginum & 72 \\
Syncope & 18 \\
Nausea and Vomiting & 20 \\
\hline Signs & \\
Abdominal tenderness & 60 \\
Tender cervical motion & 56 \\
Mass in fornix & 57 \\
Marked pallor & 39 \\
\hline Risk factors & \\
PID & 6 \\
Abortion & 10 \\
Infertility & 15 \\
Pelvic surgery & 7 \\
Unexplained & 26 \\
\hline
\end{tabular}

Table 1 shows clinical profile and risk factors of women having ectopic pregnancy. In our study majority of women were $>30$ years of age and were nulliparous.

The most common presenting symptom was lower abdominal pain ,in $88 \%$ women. On examination $18 \%$ women presented with marked pallor and shock. These women were given blood and blood products.

The diagnosis of ectopic pregnancy was suspected from clinical features confirmed on the bass of UPT, ultrasonography and serum $\beta \mathrm{HCG}$ levels.

Table 2: Mode of Treatment

\begin{tabular}{|c|c|c|}
\hline Treatment & Number & Percentage \\
\hline Surgical & 64 & $92.75 \%$ \\
Laparotomy & 57 & $82.60 \%$ \\
Laparosocpy & 7 & $10.14 \%$ \\
\hline MedicalTreatment with METHOTREXATE & 7 & $10.14 \%$ \\
\hline
\end{tabular}

Total 3 cases managed with medical treatment, out of them two cases required a lapartomy even after methotrexate so that the total number of cases manage with the laparotomy were 57 . In my study majority of patients $92.75 \%$ treated with surgery out of them $82.60 \%$ cases were treated with laparotomy and $10.14 \%$ case managed with laparoscopic surgery.

Table 3: Per Operative Findings (A) Site of EP

\begin{tabular}{|l|l|l|}
\hline \multicolumn{1}{|c|}{ Site of EP } & Number & Percentage \\
\hline TUBAL & & \\
\hline Ampullary & 44 & $63.76 \%$ \\
\hline Isthmic & 16 & $23.18 \%$ \\
\hline Fimbrial & 3 & $4.3 \%$ \\
\hline Ovarian & 3 & $4.3 \%$ \\
\hline Cervical & 1 & $1.44 \%$ \\
\hline Abdominal & 1 & $1.44 \%$ \\
\hline Comual & 1 & $1.44 \%$ \\
\hline
\end{tabular}

Table 3 : (B) Side of Tube

\begin{tabular}{|c|c|c|}
\hline Side of Tube & Number & Percentage \\
\hline Rt. Tube & 40 & $57.97 \%$ \\
\hline Lt. Tube & 27 & $39.13 \%$ \\
\hline
\end{tabular}

Table 4: Type of Surgery

\begin{tabular}{|l|l|l|}
\hline \multicolumn{1}{|c|}{ Type of Surgery } & Number & Percentage \\
\hline Conservative surgery & \multicolumn{1}{|l|}{} \\
\hline Salpingostomy & 1 & $1.44 \%$ \\
\hline Salpingotomy & - & - \\
\hline Radical surgery & 58 & $84.05 \%$ \\
\hline Salpingectomy & $58.14 \%$ \\
\hline Saipingoopherectomy & 9 & $10.14 \%$ \\
\hline
\end{tabular}

Table 5: Fate

\begin{tabular}{|c|c|c|c|c|c|}
\hline Site & Ruptured & Unruptured & $\begin{array}{c}\text { Tubal } \\
\text { Abortion }\end{array}$ & Chronic & Total \\
\hline Ampullary & 24 & 10 & 6 & 4 & 44 \\
\hline Isthmic & 13 & 2 & 1 & 0 & 16 \\
\hline Fimbrial & 1 & 1 & 0 & 1 & 3 \\
\hline Ovarian & 1 & 1 & 0 & .1 & 3 \\
\hline Cornual & 1 & 0 & 0 & 0 & 1 \\
\hline Abdominal & 1 & 0 & 0 & 0 & 1 \\
\hline Total & $\mathbf{4 1}$ & $\mathbf{1 4}$ & $\mathbf{7}$ & $\mathbf{6}$ & $\mathbf{6 8}$ \\
\hline
\end{tabular}

In my study there were fourteen patients with unruptured ectopic pregnancy. We tried medical management in seven patient, while in four patient USG showed Gestational sac more than $4 \mathrm{~cm}$ and in 2 cases $\beta$ hcG was more than 15,000 which were not fit for medical management. There were seven patient of unruptured ectopic pregnancy managed surgically.

And in another six patient surgeon had choosen laparotomy.

Table 7

\begin{tabular}{|l|l|l|l|}
\hline Region & Laparoscopy & Laparotomy & Medically \\
\hline Ampullary & $\begin{array}{l}5(19.23 \%) \\
19(73.07 \%)\end{array}$ & $\begin{array}{l}0(0 \%) \\
5(41.66 \%)\end{array}$ \\
\hline Ruptured & $6(50 \%)$ & \\
Unruptured & $1(8.33 \%)$ & \multicolumn{5}{|l|}{} \\
\hline Isthmic & $1(50 \%)$ & $1(50 \%)$ \\
\hline $\begin{array}{l}\text { Ruptured } \\
\text { Unruptured }\end{array}$ & $1(7.69) \%$ & $12(92.30 \%)$ & $0(0 \%)$ \\
Fimbrial & $1(100 \%)$ & 0 \\
\hline Ruptured & 0 & 0 & $1(100 \%)$ \\
Unruptured & 0 &
\end{tabular}




\section{International Journal of Science and Research (IJSR) \\ ISSN (Online): 2319-7064}

Index Copernicus Value (2013): 6.14 | Impact Factor (2014): 5.611

The above table 7 shows distribution of cases according to mode of treatment, site of ectopic pregnancy and fate of ectopic pregnancy

\section{Discussion}

The proportion of ectopic pregnancy was 1:320 at our institute.it is commonly found in young age group. In our study $71 \%$ women were between the age group of 21-30 years. Majority of women $30 \%$ were nulliparous. As per the study of Priti et al, $75 \%$ of the women were between the age group of 21-30 years and $36.7 \%$ women were nulliparous.

In our study, the risk factors mainly associated with women with ectopic pregnancy were history of PID, in $21 \%$ women, abortion in $7 \%$ women and infertility in $7 \%$ women. PID being the most common etiological factor and by far the most preventable, efforts for early diagnosis and prompt treatment must be developed in OPD cases itself. The Gharoro et al study in fact shows that PID was associated with $41 \%$ and previous abortion was associated with $63 \%$ of women with ectopic pregnancy.

In our study, two women had previous history of ectopic pregnancy. Out of which one woman had undergone partial salpingectomy of right tube and later had ruptured ectopic pregnancy of the isthmic part of the same tube. The other women had been operated for left sided ectopic pregnancy and later operated for right ruptured ampullary ectopic pregnancy in the form of right salpingectomy. In a study by Bennetot et al, the incidence of recurrence of ectopic pregnancy is $19 \%$ irrespective of treatment given for original ectopic pregnancy. In our study we had one patient with scar ectopic pregnancy of 6 weeks gestation.

The presenting symptoms of these women were most commonly lower abdominal pain $88 \%$ and amenorrhoea found in $69 \%$ women. In the study of Gharoro et al lower abdominal pain was present in $83.6 \%$ and amenorrhoea in $77.6 \%$ women. Fainting was experienced by $8(14.8 \%)$ women, which was due to significant intraperitoneal haemorrhage. Abdominal tenderness was present in $60(86 \%)$ women and cervical motion tenderness was present in $56(81 \%)$ women which is comparable to Majhiet et al, in which cervical motion tendernedd was present in $82.2 \%$ women.

Also a high degree of clinical suspicion of ectopic with any of the risk factors must be considered ectopic unless proved otherwise, and must be considered ectopic unless proved otherwise, and must be monitored with serial $\beta \mathrm{HCG}$ estimation and ultrasonography until localization of pregnancy is confirmed.

In the present study medical management was done in women having unruptured ectopic pregnancy and mass of ectopic gestation $<4 \mathrm{~cm}$.in our study success rateof medical treatment was $72 \%$ as laparotomy was required in two women out of 7 women who were managed by medical treatment.

Of those women who were treated either by laparoscopy or by laparotomy, salpingectomy is performed in $58 \%$, partial salpingectomy in $11 \%$ and salpingotomy in $1 \%$. In women with ruptured ectopic pregnancy, often the tube was shattered and bleeding or the ectopic mass was large . in such women, conservative surgery was not always possible and radical surgery was performed. Conservative ssurgery is not followed by aof $\mathrm{n}$ increased risk of repeat ectopic pregnancy should be taken into account when deciding on operative procedure.

In our study, laparoscopy was performed in $10 \%$ women. Laparoscopic surgery has its own advantages over laparotomy of being minimally invasive, early post operative recovery and early ambulation of patient. Ruptured ectopic does not necessarily warrant a laparotomy.and laparoscopy can be performed if bleeding is less and patient is haemodynamically stable.

In our study, successful management of ectopic pregnancy by laparotomy was higher in $82.6 \%$ women compared to laparoscopies that were successful in $10 \%$ women. This was due to the fact that before reaching to our tertiary care hospital, most of the women seek help at primary, secondary,or private health care centres or they report late. This leads to loss of precious time and women were brought wiith ruptured ectopic pregnancy with stage 2 and stage 3 shock with large haemoperitoneum requiring emergency laparotomy and transfusion of blood and blood products.

\section{Conclusion}

Analysis of 68 cases of ectopic pregnancy during the last two and half years is presented here. Ectopic pregnancy still remains potentially most critical gynecological emergency. Incidence of ectopic pregnancy is rising due to increased incidence of PID, Tubal surgery, ART. In diagnosis of ectopic pregnancy, abdominal pain and tenderness remain the most constant features along with amenorrhea. Due to revolution in technology, advanced diagnostic technique like USG, $\beta$ hcG assessment laparoscopy results in early detections even in unruptured state. Hemodynamic stability is essential for conservative management of the patient. The mortality and morbidity associated with ectopic pregnancy has reduced dramatically over last decades due to -Earlier diagnosis even in unruptured form. -Improved resuscitative measures and availability of 24 hours blood banks. -Good operative techniques and facilities. -Modern anesthetic agents and techniques. -Better antibiotic coverage. So, the mortality associated with condition is zero in my case study.

\section{References}

[1] Albucasis Quoted by King Geoden AM. J. Obst. : Gynaec.67:712,1954.

[2] Arias Stella : Atypical endometrial changes associated with presence of choripnic tissue arch pathology 58:112,1954.

[3] Berger MJ, TaymoreML : Simultaneous intrauterine \& tubal pregnancies following ovulation induction. Am. Journal Obst. Gynaec. 1972,113:812.

[4] Bukovsky I Langer R. Hariman A Caspi E.: Conservative surgery for tubal pregnancy Obst. Gynaec. 53: $709: 1979$.

\section{Volume 4 Issue 11, November 2015}




\section{International Journal of Science and Research (IJSR) \\ ISSN (Online): 2319-7064}

Index Copernicus Value (2013): 6.14 | Impact Factor (2014): 5.611

[5] Centers for disease control. Ectopic pregnancy Surveillance 1970-1978, Allanta; Georgia Centers for disease Control July 1982.

[6] Chakrawarthy S \& Shardlow J. Tubal pregnancy after sterilization Br. J. Obst; \&Gynaec. 82:58,1975.

[7] Decherney AH, Boyers SR Isthmic Ectopic pregnancy segmental resection as treatment of choice Fertil Sterile 1985, 44:307.

[8] Decherney AH, Diamond MP, Laparscopic Salpingostomy for Ectopic pregnancy Obst. \&Gynaec. 1979, 54:451.

[9] Donald Diagnostic use of sonar in Obst. \&Gynaec. Br. J. Obst. \& Gynaec. Commonwealth 72: 907-919,1965.

[10] Devendar et al.: Study of ectopic pregnancy Ind. Journal of Obst. Gynaec. Vol. 50, No. 1 Peg. 66, 2000 February.

[11]Edrnond Confino :Transcervical fallopian tube catheterization :10,158,159,160 1993.

[12]Falk HC: Tubal pregnancy Obst. \&Gynaec. 45: 215, 1975.

[13] Gary H: oral methotreaxate for treatment of ectopic pregnancy: Am J. Obst. Gynaec. Vol. 186, No. 6158 June 2002.

[14] Goshe and Goshe Ectopic pregnancy review of 119 consecutive cases. Ind. Journal of Obst. \&Gynaec. 18, 375,1968 .

[15] ICMR Taskfree project, multicentric case control study of ectopic pregnancy in India FOGS11990:4.

[16] Jain K. Hamper VM, Sanders RC comparison of transvaginal sonography in the detection of early pregnancy \& its complication. Am.J. Radiology , 1988,151:1139. 